Nuclear Instruments and Methoids $0(1982), V-203, N 1-3$, P $523-526$.

North-Holland Publishing Company

\title{
DISORDER DEPENDENCE OF ION IMPLANTED GaAs ON THE TYPE OF ION
}

\author{
I.S. TASHLYKOV \\ Institule of Applied Physics, Byelorussian Siale University, 220080 Minsk. U.S.S.R.
}

Recined 5 August 1981 and in revised form 22 December 1981

Channeling experiments with $1.0 \mathrm{MeV} \mathrm{He}{ }^{+}$ions have been carried oul to study lattice damage of (111) GaAs crystals after 60 and $110 \mathrm{keV}$ aluminum and phosphorus implantation. The implantation and the channelıng measurements have been performed in situ at $42 \mathrm{~K}$ and at room temperature (RT) Implant doses ranged from $2.8 \times 10^{12}$ to $8 \times 10^{16} \mathrm{tons} / \mathrm{cm}^{2}$.

We have observed large differences in the level of the measured damage for $\mathrm{Al}^{+}$and $\mathrm{P}^{+}$implantations into GaAs at RT within a dose range $10^{13}-10^{15}$ ions $/ \mathrm{cm}^{2}$ The chemical nature of the interaction between $\mathrm{A} 1^{+}$and $\mathrm{P}^{+}$and $\mathrm{GaAs}$ is different. Consequently, it is perposed that the effect can be explained by different types of defect formation.

\section{Introduction}

Pecularities of radiation damage, spatial distributions of implanted atoms and structural transtormations occurring during ion implantation into solids are prob. lerrs of pure and applied fields of science Conse* it is a matter of interest to study radiation d...... 5 a 45 implanted by $\mathrm{Al}^{+}$and $\mathrm{P}^{+}$jons.

Frevis: Jiments $[1-4]$ have shown the complex nature of banis: "isurder of GaAs crystals in case of $\mathrm{Al}^{+}$and $\mathrm{P}^{+}$Impliatowion $\mathrm{Al}$ interpretation of these experimental observations if often isconsistefit Consid. erable disorder of the GaAs implanted at RT with Al is explained by a non-uniform distribution of aluminum [3]. In the same work the changes of signal (combination light scattering technique), at high temperalure of implantation is accounted for by a rising rate of the target sputtering. In contrast to this conclusion, authors of ref. 2 have observed, using the electron-induced luminescence method, that the width of the layer which luminescenced in the short wave region grew to $0.4 \mu \mathrm{m}$ $\left(\bar{R}_{\mathrm{p}}=0.44 \mu \mathrm{m}\right.$ and $\Delta \bar{R}_{\mathrm{p}}=0.028 \mu \mathrm{m}$ for $E_{\mathrm{Al}}=50 \mathrm{keV}$ (j)) at high temperature implantation.

In the present work we report new observation of the implantation behaviour of GaAs, usıng $\mathrm{Al}$ and $\mathrm{P}$ implants with energy 60 and $110 \mathrm{keV}$. The production of damage as a function of the ion dose both at low and room temperatures has been determuned.

\section{Experimental}

GaAs single crystals of (111) orientation were implanted by $\mathrm{Al}^{+}$and $\mathrm{P}^{+}$ions at energies 60 and $110 \mathrm{keV}$. Implantation was carried out along nonchanneling di. rection both at $42 \mathrm{~K}$ and room temperature, using a magnetically analyzed and swept ion beam in a vacuum system with base pressure in the $10^{-7}$-Torr range. Implantation doses, ranging from $2.8 \times 10^{12}$ to $8 \times 10^{16}$ ions $/ \mathrm{cm}^{2}$ were obtained. The average beam intensities were $70-160 \mathrm{nA} / \mathrm{m}^{2}$ at $60 \mathrm{keV}$ and $20-70 \mathrm{nA} / \mathrm{cm}^{2}$ at $110 \mathrm{keV}$. The damage-dose behaviour of ion bombarded GaAs was measured by the channeling technique using in situ measurements.

For both the $42 \mathrm{~K}$ and $300 \mathrm{~K}$ bombardments the sample was surrounded by a $30 \mathrm{~K}$ cold shield to minimise any surface contumuation during the experiment

Energies of backscattered ions were measured using a surface barrier detector at $150^{\circ}$ scattering angle. The entrgy resolution was $15 \mathrm{keV}$ at fwhm. Radiation damage was calculated using an iterative technique based upon á linear dechanneling approximation.

\section{Results}

In fig. I the backscattering specira are shown for $\mathrm{Al}^{+}$and $\mathrm{P}^{+}$implanted GaAs crystals. Curves 3 and 4 show the RBS spectra from crystals implanted by $\mathrm{Al}^{+}$ and $\mathrm{P}^{+}$at $42 \mathrm{~K}$, respecuvely. The curves indicate that at low temperature $\mathrm{A}]^{+}$and $\mathrm{P}^{+}$implantations result in similar level of radiation damage. Also the position and fwhm of the damage peak in the case of low and moderate doses of $\mathrm{Al}^{+}$and $\mathrm{P}^{+}$implantations into GaAs ar $42 \mathrm{~K}$ are comparable.

The pecture is different for RT irradiation. Curve 5 shows lite backscattering spectrum from GaAs, Implanted at RT by $1.4 \times 10^{13} \mathrm{Al}^{+} / \mathrm{cm}^{2}$ and curve 6 shows a sirular spectrum for $1.4 \times 10^{14} \mathrm{p}^{+} / \mathrm{cm}^{2}$ irradiation of GaAs. Despite the fact that phosphorus implantation is one order of magnitude less than that of Al, the peak of the damage caused by $\mathrm{Al}^{+}$irradiation is consid- 
erably less than that due to $P^{+}$irradiation

At high fluences $\left(D>4 \times 10^{15}\right.$ ions $\left.\mathrm{cm}^{2}\right)$ of implants when amomhisation has been achieved the

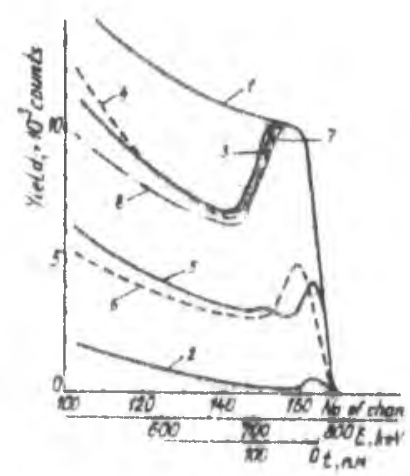

Fig I Backscallering spectra of GaAs using $10 \mathrm{MeV} \mathrm{He}{ }^{-t}$ for random - 1 and (111) channeling before implantation -2 and after implantation at $42 \mathrm{~K} 1.4 \times 10^{14} \mathrm{Al}^{+} / \mathrm{cm}^{2}-3: 1.35 \times 10^{14}$ $\mathrm{P}^{4} / \mathrm{cm}^{2}-4$; at room lemperature $14 \times 10^{15} \mathrm{Al}^{1}-5 ; 14 \times 10^{14}$ $\mathrm{P}^{+} / \mathrm{cm}^{2}-68.1 \times 10^{19} \mathrm{Al}^{+} / \mathrm{cm}^{2}-7: 4.1 \times 10^{19} \mathrm{p}^{4} / \mathrm{cm}^{2}-8$

aligned spectrafrom both $\mathrm{Al}^{+}$and $\mathbf{P}^{+}$implanted GaAs crystals are again very similar (curves 7 and 8). How. ever, we note, that to amorphise the GaAs crystals by $\mathrm{Al}^{+}$implantation approximately one order of magni. tude higher fluxes (compared $10 \mathrm{P}^{+}$) have to be used

Damage versus dose curves are shown in fig. 2. A low temperature, when migration processes are frozen. the dynamics of damage accumulation seems to be similar for both $\mathrm{Al}^{-4}$ and $\mathrm{P}^{+}$irradiation (curves 1 and 2) We note. that the amount of damage resulting from $\mathrm{Al}^{+}$implantation is consistently tower.

Al RT there are essential differences in the damage dose dependence observed for $\mathrm{Al}^{+}$and $\mathrm{P}^{+}$implanta. tions into GaAs (curves 3 and 4 in fig. 2). These curves have three distinct regions, each with a different slope.

Fig. 3 shows defect distribution profiles in GaAs crystals implanted by $110 \mathrm{keV} A]^{+}$and $P^{+}$ions $A$

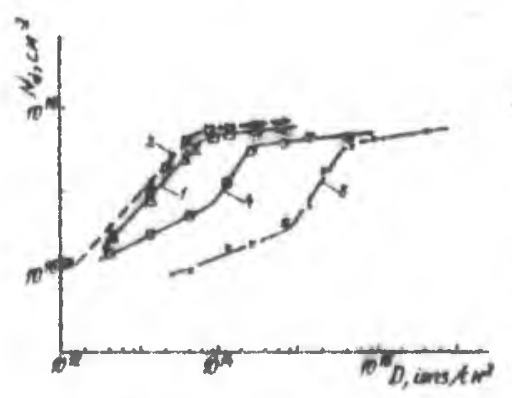

Fig. 2. The dose dependence of the lattice disorder produced in GaAs by $60 \mathrm{keV} A 1$ and $P$ implantations a $42 \mathrm{~K}-1$ and 2, and room temperature -3 and 4, rexpectively.

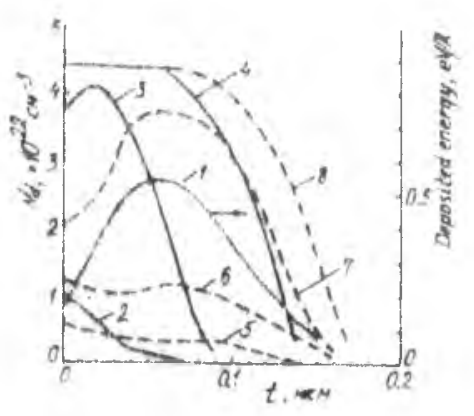

Fig 3. Defect distributon profiles in $110 \mathrm{keV}$ t.m maplanted at room comperature GaAs: $2.8 \times 10^{14} \mathrm{Al}^{+} / \mathrm{cm}^{2}-2,9.0 \times 10^{16}$ A) ${ }^{-1} / \mathrm{cm}^{2}-3: 1.8 \times 10^{16} \mathrm{Al}^{+} / \mathrm{cm}^{2}-4: 2.1 \times 10^{13} \mathrm{p}^{+} / \mathrm{cm}^{2}-5$; $5.3 \times 10^{13} \mathrm{p}^{+} / \mathrm{cm}^{2}-6,1.4 \times 10^{14} \mathrm{p}^{+} / \mathrm{cm}^{2}-7 ; 3.5 \times 10^{14}$ $\mathrm{p}^{+} / \mathrm{cm}^{2}-8$. A theoretical profile of deposited anergy in $\mathrm{P}^{+}$ radiated GaAs - 1.

profile of deposited energy in $P^{+}$radiated GaAs [6] is shown for comparison the energy deposition of $\mathrm{Al}^{-1}$ in GaAs is distributed $-10 \mathrm{~nm}$ deeper than that for $\mathrm{p}^{+}$ ions [6] The energy scale of the backscattered $\mathrm{He}^{+}$has been converied into a depth scale using conventional energy-Inss parameters $\{8\}$

\section{Discussion}

The RBS in conjunction measurements have indicated that

K) $\mathrm{Al}^{+}$and $\mathrm{P}^{+}$implantation into $\mathrm{GaAs}$ similar picture of the damage in the implanted crystal. curves 3 and $A$ in $f(g)$. For both sorts of ions implanted at low temperature in GaAs the build up of damage with dose is initially linear and the constant of proporlionality is about unity. curves 1 and 2 in fig. 2. Eventually, saturation occurs and the saturation level is reached al doses of approximately $5 \times 10^{13} \mathrm{P}^{+} / \mathrm{cm}^{2}$ and $6 \times 10^{13} \mathrm{Al}^{+} / \mathrm{cm}^{2}$. The thickness of amorphous layer grows slowly with dose but the number of defects produced by $A t^{+}$in GaAs is always less than that for $P^{2}$ ions.

Several possible reasons for this hebsviour can be suggested The effect is possibly associated with the lower fraction (0.55 compared with 0.59 ) of the total energy deposited into nuclear recolls by $\mathrm{Al}^{+}$implantation In addition. the teat of the lotal teleased eners is bigger in the case of Al implan's Consequently, if at 42 $K$ annealing processes during implantation exist, they may occur in more active form peo in $\mathrm{Al}^{+}$radiated GaAs crystals

As mentioned in section 3. the picture differs for room temperature implantation. Curves 5 and 6 in fig. 1 discussed above demonstrate this conclusion. We can add that the ptak of the damage caused by $\mathrm{Al}{ }^{+}$irradia- 
tion is considerable less than that due to $\mathrm{P}^{+}$implantation. A characteristic feature of $\mathrm{Al}^{+}$implantation is also the smaller depth of the damage peak position (compared with $\mathrm{P}^{+}$implantation and theoretical prediction [5.6]). This fact is reflected in fig. 3 as well.

As a result, there are essential differences in the damage dose dependence observed for RT Al ${ }^{+}$and $\mathrm{P}^{+}$ implantations into GaAs (curves 3 and 4 in fig. 2). These curves have three distinct regions each with different slope. The first region (doses up to $\sim 1 \times 10^{14}$ $P / \mathrm{cm}^{2}$ and $\sim 1 \times 10^{15} \mathrm{Al}^{+} / \mathrm{cm}^{2}$ ) can be considered as a stage of defect accumulation. The slower rate of rise of the curve of damage with dose compared with the curves obtained at the low temperature experiment (curves 1 and 2 in fig. 2), is considered to be due to annealing of the damage, produced in GaAs both by $\mathrm{Al}^{+}$and $\mathrm{P}^{+}$implantation and by the $1 \mathrm{MeV}$ helium beam used subsequently for analysis.

Similar stages of defect accumulation were observed in $\mathrm{Si}$, implanted at RT with $\mathrm{B}^{+}$and $\mathrm{N}^{+}$using secondary-emission technique [7] and in GaP, wht has implanted at RT with $\mathrm{Te}^{+}$ions (RBS measurements) [9]. The authors of both papers consider that at this stage processes of simple interaction of radiation defects (plus impurities) and the creation of stable complexes in implanted layers take place.

Our observations are in good agreement with such interpretations of experimental results. We can add. that the chemical nature of the interaction between $\mathrm{Al}$ and $P$ atoms and GaAs (the atoms create chemical bonds with $\mathrm{As}$ and $\mathrm{Oa}$ atoms respectively) is probably responsible for essential differences in the level of radiation damage at that stage in the dose range up 10 $-1 \times 10^{15}$ ions $/ \mathrm{cm}^{2}$. It is known that lattice constants are quite different for GaAs $\left(a_{0}=5.6532 \AA\right)$ and $G a P$ $\left(a_{0}=5.4512 \dot{A}\right)$ and almost the same for GaAs and AlAs. This means that lower energy migration processes would take place in $\mathrm{Al}^{+}$implanted rather than in $\mathrm{P}^{+}$ implanted GaAs. The annealing effect therefore will be bigger in GaAs radiated by $\mathrm{Al}^{+*}$ ions. On the other hand different defect mobilities may lead to the formation of different types of secondary stable cripplexes. Our results confirm such assumptions. For example, in spite of the smaller peak of the damage caused by $\mathrm{Al}^{+}$irtadiation (curve 3 in fig. 1) the dechanneling rate is. even higher than that observed for $\mathrm{P}^{+}$implantations (curve 6).

Recent publications indicate the possibility of using a channeling technique (by mean of measuring dechanneling rate different energy of analysed jons) to estimate types of defects in implanted crystals $[10,11\}$. At present we are planning to apply this technique to analyse types of damiage in $\mathrm{Al}^{+}$and $\mathrm{P}^{+}$radiated GaAs.

The first region in fig. 2 is followed by a stage of damage iransformation. the onset of which is at $-10^{14}$ $\mathrm{P}^{+} / \mathrm{cm}^{2}$ and $\sim 10^{15} \mathrm{Al}^{+} / \mathrm{cm}^{2}$. The rate of inetease of damage with dose becomes greater at the second stage. as shown in fig. 2. until a saturation level is reached. The implanted layer can thus be considered to be in a random or amorphous condition to a depth corresponding to the projected range plus a range of spread (curves 7 and 8 in fig. 1). The damage transformation takes place at damage levels of $\sim 20$ and -10 percent total disorder in $\mathrm{P}^{+}$and $\mathrm{Al}^{+}$implanted GaAs, respectively. These levels agree qualitatively with the estimates of previous investigations $[7.9 .12]$.

The final region is a slow increase in amount of damage. In accordance with the changes in the RBS spectra this is considered to be due to the increase of the damage layer thickness. This means that the effect of the surface sputtering plays negligible role for $\mathrm{Al}^{+}$ and $\mathrm{P}^{+}$ion doses up $108 \times 10^{16} \mathrm{~cm}^{-2}$.

The energy of the ions was increased to $110 \mathrm{keV}$ in order to restrict the surface influence of GaAs damage dependence on ion sort of implants. But in the experiments with $110 \mathrm{keV} \mathrm{Al}^{+}$and $\mathrm{P}^{+}$implantations into GaAs, differences in the level of damage have been estimated to be even bigger than for $60 \mathrm{keV}$ jons. Data, presented in fig. 3. illustrate this behaviour. One may compare the experimental and theoretical damage profiles in $\mathrm{Al}^{+}$and $\mathrm{P}^{+}$implanted GaAs crystals. The experimental defect profile in $1.4 \times 10^{14} \mathrm{P}^{+} / \mathrm{cm}^{2}$ implanted GaAs is consistent with the calculated mean of the damage depth, while for low doses the concentration of defects at the surface is higher. than, or approaches, the concentration of $N_{\mathrm{d}}$ at the expected depth of the maximum position of the deposited energy distribution. Formation of the two damage peaks (the "interior" at a depth $\bar{R}_{p}$ and on the "surface") is a known effect in implanted semiconductors $[7,13,14]$. We have previously discussed [4] high cencentration of radiation defects localized on the surface at the implanted at $T=150^{\circ} \mathrm{C}$ by $\mathrm{P}^{+}$GaAs crystals. In the case of $\mathrm{Al}^{+}$ implantation into iaAs only on the "surface" peak of damage is usually irmed. The depth distribution of the damage profiles in $\mathrm{Al}^{+}$implanted at RT GaAs crystals can be compared with theoretical prediction only for large doses when the amorphisation of the surface layer takes place (curve on fig. 3). For low and moderate dose ranges (curves 2 and 3 on fig. 3 ). the radiation defects are concentrated at the crystal surfare wit layer thickness which is a factor of I? predicted mean of the damage dop it:

\section{Conclusions}

In this paper we have studied lattice damage caused by jon implantation at low $(42 \mathrm{~K})$ and room tamperalures in OaAs using $A l$ and $P$ ions up to $110 \mathrm{keV}$. In particular, the dapendence of disorder on implanted ion dose and depth distribution of damage have boen 
investigated. For both sorts of rons implanted at his temperalure, the build up of damage with dose is lumbl with the constant of pioportionality close to unity ibtibl an ainorphisation of the implanted layer is reacthed at a dose of approximately $5 \times 10^{13} \mathrm{P}^{+} / \mathrm{cm}^{2}$ and $6 \times 10^{13}$ $\mathrm{Al}^{+} / \mathrm{crn}^{2}$.

The increase of darrage with ion dose in Ga.As implanted at RT exibuts three linear regions: a) a slow build up of danage to approxumately 20 and 10 percent of saturation level at $1 \times 10^{14} \mathrm{P}^{+} / \mathrm{cm}^{2}$ and $1 \times 10^{15}$ $\mathrm{Al}^{+} / \mathrm{cm}^{2}$, respecuvely; b) a faster increase of damage to the saturation level of disorder at a dose of approximately $3 \times 10^{14} \mathrm{P}^{+} / \mathrm{cm}^{2}$ and $\left.4 \times 10^{15} \mathrm{Al}^{+} / \mathrm{cm}^{2} ; 0\right)$ a very slow increase in the number of defects due to enlargement of the damaged layer thickness.

large differences in the level of measured disorder (up io) one order of magnilude) have been observed for $A t$ and $P^{+}$implantations into GaAs at RT within the duse range $10^{13}-10^{15}$ ions $/ \mathrm{cm}^{2}$. This effect indicates th.st the chemical nature of the interaction between $\mathrm{Al}$ and $P$ atoms and Gass substrate is different and plays an important role in linutalist of migration processes in the implanted layers

In $\mathrm{Al}^{+}$implanted ai $\mathrm{KT}^{-} \mathrm{T}$ ino $\mathrm{G}$. As, radiation defects thure mobile than in $\mathrm{P}^{+}$implanted crystals There urface" and the "interior" damage peaks exist ted crystals while in gaAs, implanted e" peak is formed.

The authot wh. as. at iss his thanks to Dr.

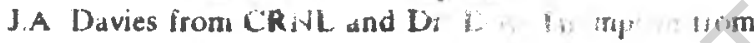
MiMaster Unversity for many critical and helpful discussions of the experimental results, and to $\mathrm{Mr}$. $\mathrm{R}$ Newcomb for useful assistance.

The experimental part of this investigation has been done at McMaster Universily under the General Exchange Agrement between the USSR and Canada We express our athnowledgments to the SSHKC of Canada for providing of sumable conditions to do this research

\section{Heferences}

[1] L.H Skolnik, W.G. Spitzer, A Kahan and R G Huns. pereer, J. of Appl Phys. 42 (1971) 5223.

[2] ON. Kuzretsov, L.V. Lezheiko. E.V. Lubupylova and LN Safronov. Fisika and Tekhnika Foluprovodnikov 11 (1977) 1449

(3) II. Novak, V.V. Bapuzmanski. N.S. Smirnova and A.V. Suvorov, Fisika Tvjordogo Tela 20 (1978) 2134

[4] I.S Tashlykov, Nucl. Instr and Meth 170 (1980) 403

[5] A.F Burenkov, F.F Komarov, M A. Kumakhov and M.M. Tjomkın, Tables of the Ion Implanted Spatial Distribution Parameters (Byelorussian State Universitys Publishing House, Minsk, 1980).

[6] K.B Winterbon, Ion Implantation Range and Energy Deposituon Distritiutuons. vol. 2: Low Incidert Ion Energy (IFl/Plenum, New York, 1975).

[7] I.A. Abrojar. A.I. Titov and A.V. Khlebalkin, Fistia and Tekhnika Poluprovodnikov 13 i1979) 227.

[8] Ion Bean Handbook for Materials Analysıs, ed J.W. Mayer and E Rimus (Academic Press. New York, 1977).

[9] G. Carter, W.A. Grant, J.D. Haskeil and G.A. Stephens, Rad. Effects 6 (1970) 277.

110) S.T Picraux, E. Rumin, G. Foti and S.U Campisano, Phys. Rev, B 18 (1978) 2078

[11] G. Goblz, B. Gruska and H. Hedler, FSU Jena, Forschungsergebrisse No. 42 (N) (1978) 1.

[12] [).A. Thompson and R.S Walker, Rad Effects 30 (1976) 37.

(13) S I. Romanov and L.S. Smimov, Fisika and Tekhnika Poluprovodnikov 6 (1972) 1631

[14] D.K. Sadana and G.R. Booker, Rad. Effects 42 (1979) 35. 